\title{
RFID-GSM imparted School children Security System
}

\author{
K. Vidyasagar \\ Dept. of ECE, SSIT \\ Sathupally, T.S, India
}

\author{
G.Balaji \\ Dept. of ECE, SSIT \\ Sathupally, T.S, India
}

\author{
K.Narendra Reddy \\ Dept. of ECE, SSIT \\ Sathupally, T.S, India
}

\begin{abstract}
With the advancement of the crime rate security is having its alarming significance for school children's. The safety mechanism to the transportation bus and to the children travelling from home to the school and resume back to home is a standalone component to the parents and to the school management. This paper aims to provide the total security for school children. Range and Obstacle detection and accident detected sensors are implanted on the front surface of the bus in order to avoid collision with another vehicle on the Road. Each student is tagged with unique code. Two counters used at the entrance and exit location of the bus. Wireless communication technology (IEEE 802.4.15) is used to inform the status of the bus to the school principal. The absentee record of the student will be send to the concerned parent before leaving the children entry point. The return information is also informed to the parent using GSM technology. The results are favorably good to meet the challenges of the security issues.
\end{abstract}

\section{Keywords}

RFID, IEEE 802.4.15, GSM

\section{INTRODUCTION}

School children safety is the most significant component encouraged to precede research with the support of advanced technology. Several bitter incidents forced to develop an innovative methodology to provide secure life for children. Parents are unable to feel comfortable until the child resumed back to home safely. Missing of the students at school premises, anti social elements kidnappings etc are increasing in an advance. Technology should be imperative to safe guard the society. The developed working model considered RF ID Technology and an advanced ARM 7 processor and GSM technology. The status of the children is readily available with the school principal and with the parent time to time. The return status of the child is secured by providing the message to the parent in advance is encouraged to meet the challenges in the children security. The working model is developed and tested periodically for constant monitoring.

\section{LITERATURE SURVEY}

Khaleed shaban adopted RFID Technology to safeguard the children from wrong identification of their destination location, method to curtail the students sleeping in the bus its self without leaving to classes. This paper also focused to provide the security to the children from starting location to the destination point with applied RF technology [1].

Seong Shaban described the security of the children at school Zone premises. This paper adopted a wireless sensor network methodology to identify the vehicle license plate number while moving with high speed. This paper also focused to trace the unauthorized parking vehicles at the school zone premises to safe guard the children from the accidents from the hidden zone areas [2].

G. Bharathi, L.Ramurthy proposed a mechanism to trace the missed student using GSM- GPS technology. An ARM 7 is used to process the given information and to send the appropriate location of the missed student by adopting the GSm technology. The Missed student Latitute and Altitude locations are determined by adopting the GPS Technolgy [3][6][7].

V. Sivasankaran et.al proposed a RFID -GSM technology to provide the security to the school children. The RFID tags are attached to the children bags for tracking and GSM is used to send the messages to the parents [4].

M. Navya et.al Proposed GSM-GPS technology to track the children students. GPS is used for identifying the student location. GSM is used to send the information to the parent android mobile. Monitoring database is provided at the control room of the school [5].

\section{HARDWARE COMPONENT DESCRIPTION}

\subsection{Range detection and obstacle detection device}

The Module consists of transmitter and receiver. The device will sense the object span of 0.02 to 4 meters.

10 Micro sec triggering pulse is applied to start the ranging. The module releases $40 \mathrm{kHz}$ ultrasound for eight successive cycles. Then the echo line goes high. Any object in the line of sight the device listen the echo and lowers its echo line. The width of the pulse is proportional to the distance of the object. if no object is detected the echo line is pulsed low after $30 \mathrm{~m}$ sec.

The range of the object in inches $=$ width of the pulse $/ 148$ The device is able to trigger for every 50 micro seconds. So, the device can scan for objet 20 times in a second. If any object is detected against the bus the output signal of the micro controller causes to regulate the speed of the bus. The collision can be curtailed to the maximum extent.

\subsection{Vibration sensor}

A vibration sensor is positioned in the bus to detect the collision with another vehicle on the bus. Any accident may causes to deviate the neutral axis of the piezo electric crystal. The output signal across the axis of the piezo electric cryptal is measured in terms of voltage. Total indicator reading (TIR) is used to determine the total vibration number. i.e The difference between the maximum positive and negative amplitude of the signal is used to determine the total vibration. This signal is interfaced to ARM 7 microcontroller. The processed signal is transmitted to the school principal and to the authorities using Global system for mobile communication GSM. 


\subsection{RFID Reader}

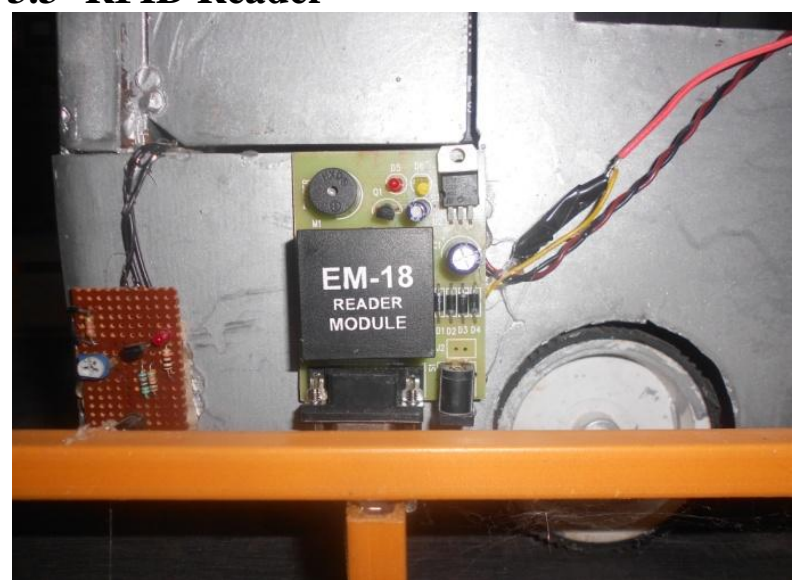

Fig. 3.1 RFID reader and vibration sensor at the entrance of the bus

Each student is housed with RF identity card. The indentifying information stored in the microchip transmits to the RFID reader using an antenna. RFID reader is equipped at the entrance and exit gate of the bus. The reader will communicate to the ARM7 microcontroller serially using the line driver MAX 232 to verify the threshold value. Fig.3.1 shows EM 18 used as a RFID reader. FIG 3.2 shows the controlling circuit of the bus

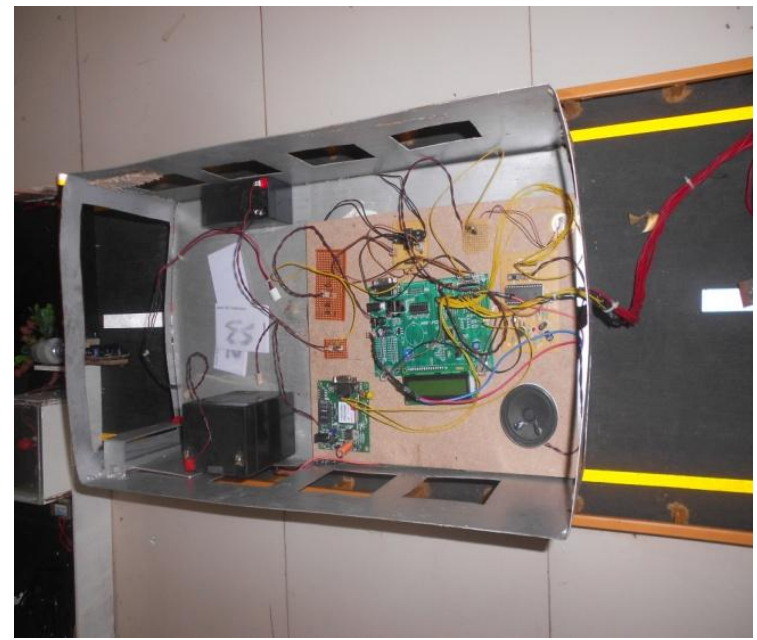

Fig. 3.2 Control circuit view of school bus

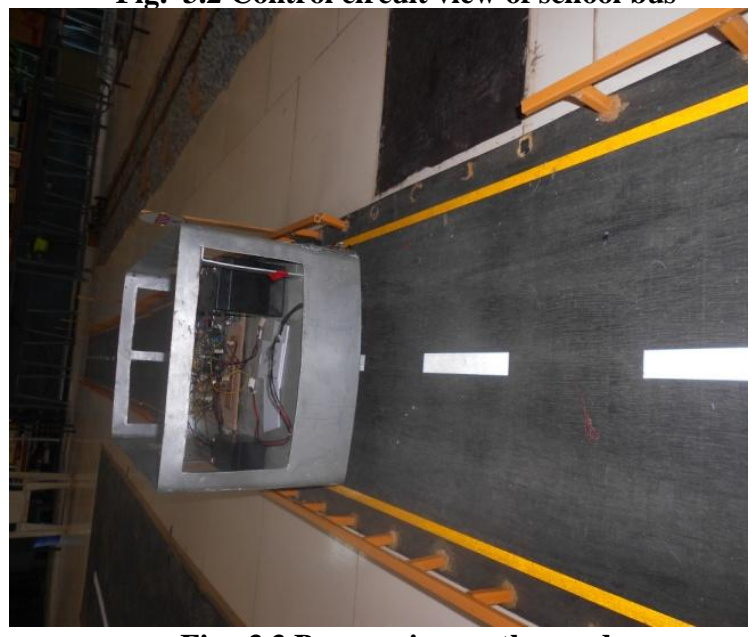

Fig. 3.3 Bus moving on the road

\subsection{Communications}

Global system for mobile communication (GSM) is adopted to communicate with the parents and to the school principal. The mode of data transmission is through SMS only. The microcontroller will communicate with the GSM modem serially via MAX 232 line driver. The MAX 232 will convert TTL logic levels to Serial logic levels.

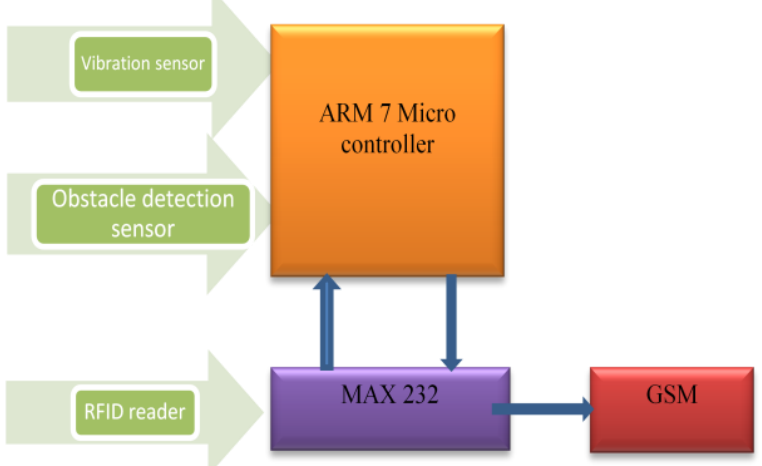

Fig. 3.4 The flow of signal information

\subsection{Controller}

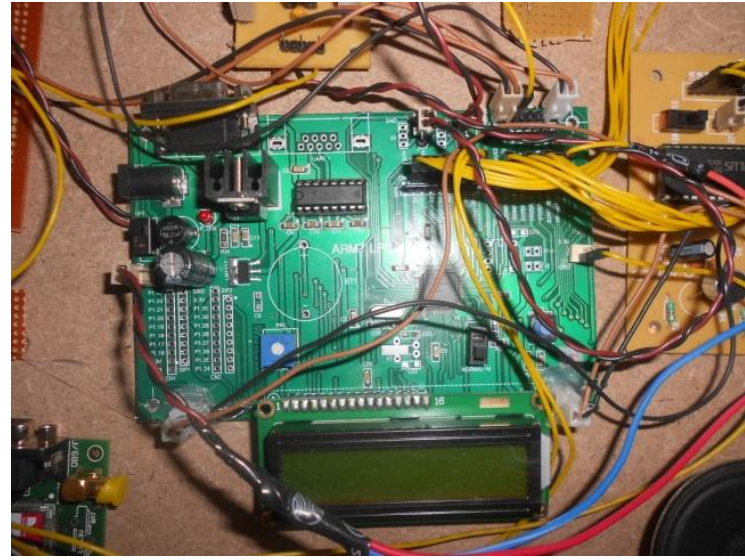

Fig. 3.5 ARM7 interfaced to school bus.

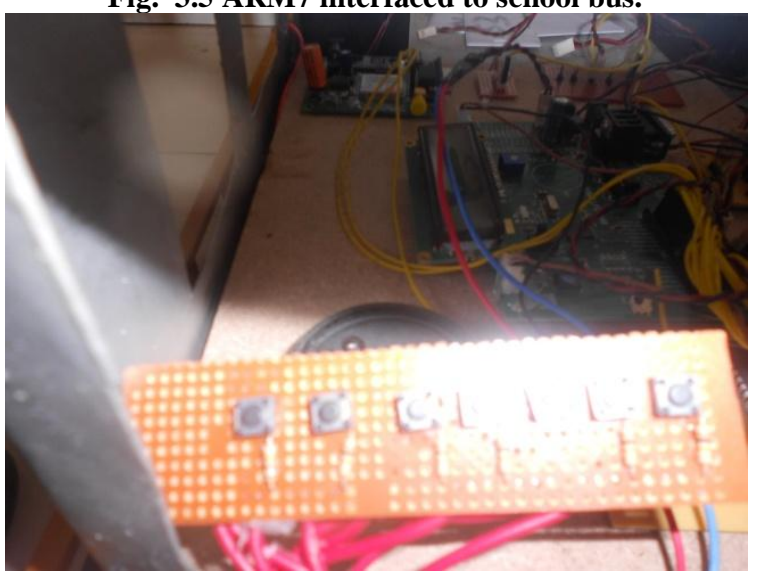

Fig. 3.6 Bus driving switch mechanism

ARM 7 micro controller is used to process the acquired input signals. UP counter is required to record the number of students occupied in the bus and to send the status information to the concerned authorities. The down counter is required to empty the bus with children. The speed of processing is obtained with 128-bit interface / accelerator. Multiple serial 
interfaces are supporting to meet the demand of the work, RFID reader to Micro controller and microcontroller to GSM. Fig 3.5 ARM 7 interfaced to the Wireless communication device i.e IEEE 802.15.4 Fig 3.6 shows the switching mechanism to drive the school bus.

\subsection{Theoretical Calculations}

For stable movement of the school bus the required spinning force of the motor is calculated. Four DC motors are used to drive the school bus. Four driving switches are used to position the bus forward, left, right and stop positions. The driving signals from the input switches are given as inputs to the microcontroller. The microcontroller will drive the motor driving circuitry (L293D) to enable the motion of the school bus. The torque required to drive the bus is proportional to its weight.

The measured weight of the School bus is 98.06650 Newton, and the shaft length is 0.03 meters.

Torque required $=$ Force $*$ Distance $=98.06650 * 0.03=2.9419$ Newton-Meters.

\subsubsection{For School bus linear motion}

The power $[$ watts] $=$ Force $[$ Newton] $*$ velocity [Meter/ Second]

The calculated required power $=98.06650 * 0.1=9.80$ watts.

The motor shaft angular motion is to be estimated .i.e

The angular velocity of motor under no load is $100 \mathrm{RPM}$.

The product of torque and the rotational distance per unit time is equated with power.

Prot $=\mathrm{M}^{*} \mathrm{~W}$

Where Prot $=$ Rotational mechanical power

$\mathrm{M}=$ Torque

$\mathrm{W}=$ Angular velocity

Angular velocity $\mathrm{Wrad} / \mathrm{sec}=100 *[2 * \Pi / 60]=10.46 \mathrm{rad} /$ sec

Power required to drive a torque load of 2.9419 Newton / meter

$=$ Torque Load $* 100 \mathrm{rpm} *$ conversion factor

$=2.9419 * 100 * 0.1047=\mathbf{3 0 . 8 0 1 6}$ Watts

Rotational mechanical power $\mathrm{P}$ rot $=30.8016$ Watts

Output shaft torque $\mathrm{M}=2.9419$

Motor current estimated $(\mathrm{I})=\mathrm{M} / \mathrm{K}$

Where $\mathrm{K}$ is torque constant $=1.22 \mathrm{NM} / \mathrm{A}$

The resistance $(\mathrm{R})$ of the motor $=3.3 \mathrm{Ohms}$

Drive voltage $\mathrm{U}=\mathrm{R} * \mathrm{I}+\mathrm{K}^{*} \mathrm{~W}$

Where $w$ is Angular velocity

Motor current $\mathrm{I}=0.57 \mathrm{~A}$

Estimated Drive Voltage $=14.64 \mathrm{~V} \mathrm{dc}$

Rated voltage $=15 \mathrm{~V} \mathrm{dc}$

\section{METHODOLOGY}

Step 1: Initialization of the ports

Motors initialization

Motor 1 to port $0.0 \& \mathrm{p} 0.1$

Motor 2 to port $0.2 \& \mathrm{p} 0.3$

LCD initialization

Rs pin to port 0.4

$\mathrm{Rw}$ pin to port 0.5

En pin to port 0.6

Data lines- D0 to port 0.7

D1 to port 0.8

D2 to port 0.9

D3 to port 0.10

Vibration sensor to $\mathrm{p} 0.11$

RFID Reader to 00.12

IR Sensors $1^{\text {st }}$ Stage to port 1.0

$2^{\text {nd }}$ Stage to port 1.1

$3^{\text {rd }}$ stage to port 1.2

$4^{\text {th }}$ Stage to port 1.3

GSM Module (2 pins)

Txd to port 1.5

Rxd to port 1.6

Buzzer to port 1.7

Step 2: Read the vibration sensor at port 0.11

If the voltage is $5 \mathrm{v}$ then stop the bus. Send the message to the principal and police.

Else go to step 3

Step 3: Read the RFID reader at stage 1

If the tag found then increment the counter

Else

Send the messasge "your child is Absent " to parent

Step 4: Enabling the bus driving mechanism

Step 5 : Read the RFID reader at stage 2

If the tag found then increment the counter

Else

Send the message "your child is absent" to parent Repeat step 3 to 4 for next two stops

Step 6: Check the destination point

Verify the counter

If the count $=0$

Then send the message "route no"-"bus no -", children strength to principal

Step 7: Re enable the RFID reader and the down counter.

If the count is desired value then start the bus

Else wait ( )

Step 8: Enable the preloaded audio device.

Send the message "Your ward is close to destination" to parent.

Enable the announcement "Station name".

Decrement the counter.

Step 9: Stop.

Repeat the step 8 until the count is zero.

\section{RESULTS AND ANALYSIS}

Fig 5.1, Fig 5.2, Fig 5.3 represents the positions of the bus at various stop points. Fig 5.4 represents the status of bus to the school principal. If any student entry at particular location is not detected the absent status is send as an SMS to the concerned parent. Fig 5.5 shows the absent information sends to the parent. Fig 5.6 represents the status of the student's entry to the school premises. Fig.5.7 represents the destination arriving status of the student is send to the right parent. This developed methodology is also providing station enouncement in a loud voice. The results obtained are favorably good to meet the expectations of the school children security.

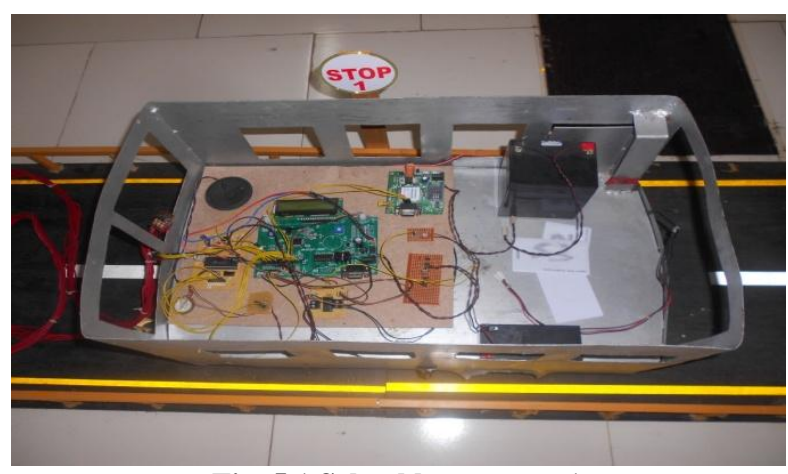

Fig. 5.1 School bus at stop 1 


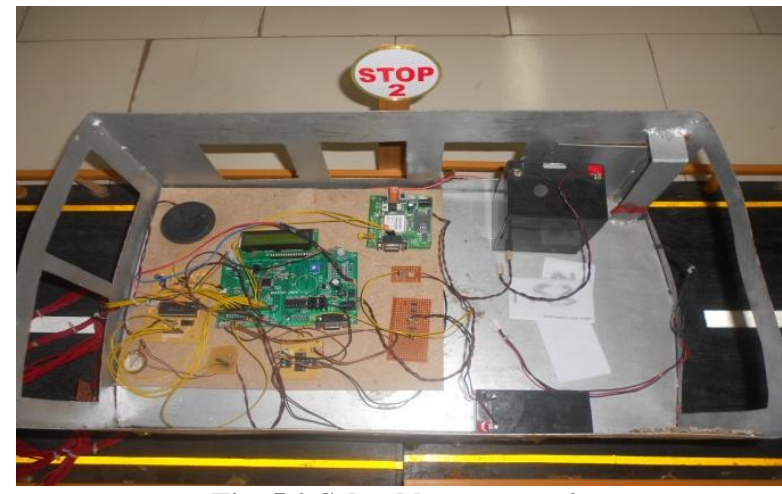

Fig. 5.2 School bus at stop 2

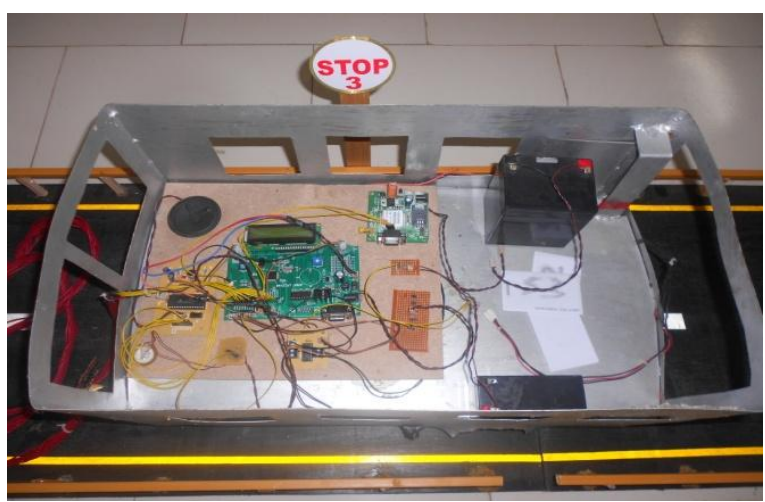

Fig. 5.3 School bus at stop 3

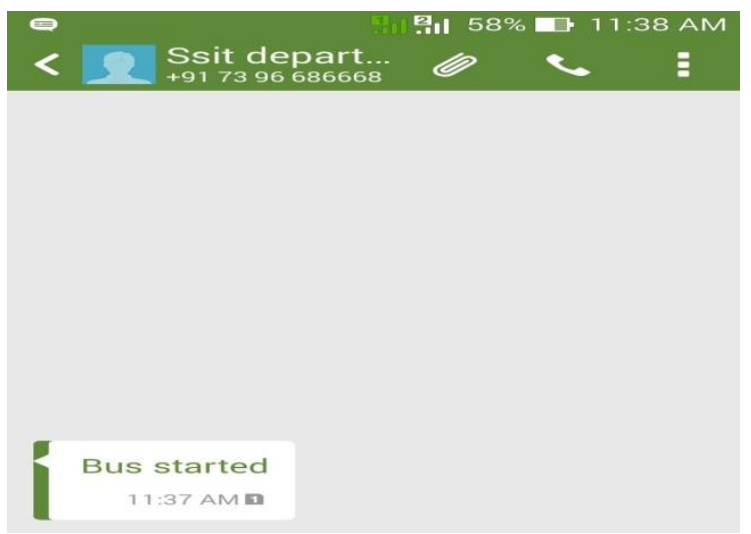

Fig. 5.4 SMS send to Principal

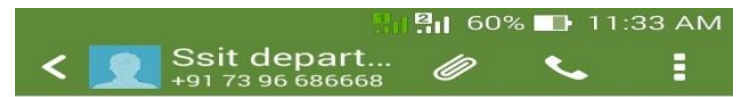

Your child is absent today

11:29 AM I

Fig. 5.5 SMS Send to parent

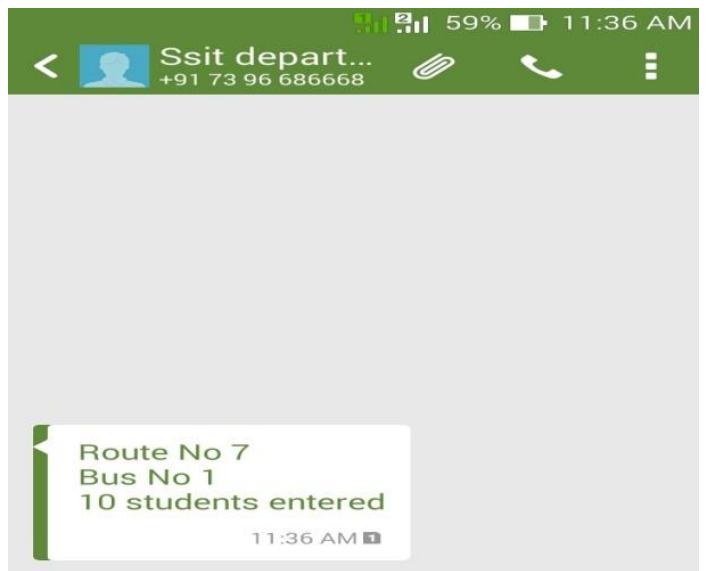

Fig. 5.6 SMS send to principal

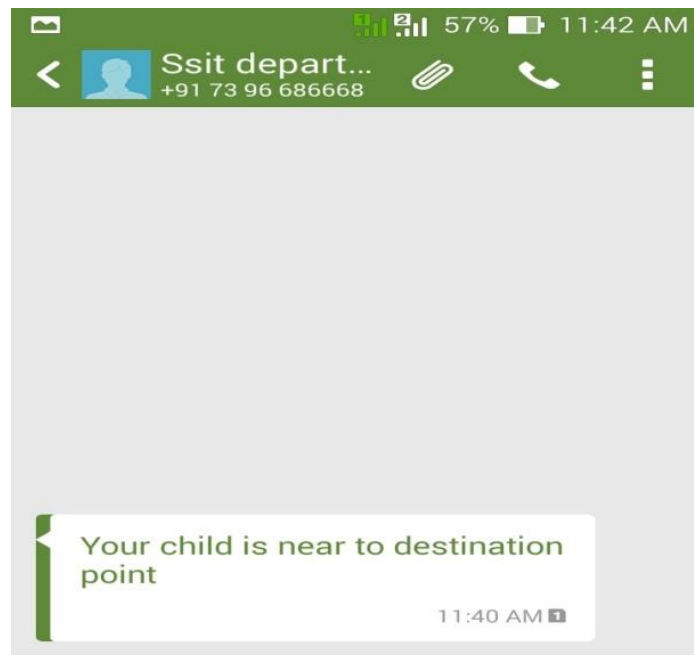

Fig. 5.7 SMS send to parent

\section{CONCLUSION}

The developed working model is implemented on 30 feet length road constructed in the laboratory. The bus driving mechanism is able to move the bus with no deviations and the children security imparted to promote for real time applications. While returning to their home with this mechanism no student is permitted to move away from security without knowing the authorities. The return information message is sending to the parent in an advance will be an added advantage of the children from kidnapping.

In future this proposed methodology is enhanced with anti collision mechanism and biometric system is to be proposed to replace with the existing RFID technology.

\section{ACKNOWLEDGEMENT}

The authors like to express sincere thanks to the management and principal of Sai Spurthi Institute of Technology for providing the fund and necessary infrastructure. In future the proposed methodology is to be modified by introducing the biometric thumb system

\section{REFERENCES}

[1] Khaled Shaaban et.al "Smart Tracking System for School Buses Using Passive RFID Technology to Enhance Child Safety", Journal of Traffic and Logistics Engineering, Vol 1( 2), pages: 191-196, Dec 2013. 
[2] Seong-eun Yoo, Poh Kit Chong, Daeyoung Kim, "School Zone Safety System Based on Wireless Sensor Network", Journal of Sensors, Vol 9, Pages 5968-5988, July 2009.

[3] G. Bharathi, L.Ramurthy , “ Implementation of children tracking system using ARM7 microcontroller", International Journal of Industrial Electronics and Electrical Engineering, Volume-2(12): pages 18-21, Dec.-2014.

[4] V.Sivasankaran et.al , " Advanced embedded system assisted GSM and RFID based smart school management system", International journal of advanced research in electrical , Electronics and Instrumentation Engineering, Vol 2(7): pages 3124-3128, July 2013.

[5] M.Navya, et.al , “ Android based children tracking system using voice recognition", International journal of Computer science and information technology, Vol 4 (1): pages 229-235, Jan 2015.

[6] Khaled Shaaban et.al, "Smart Tracking System for School Buses Using Passive RFID Technology to Enhance Child Safety “, Journal of Traffic and Logistics Engineering, Vol 1(2): pages 191-196, Dec 2013.
[7] J.Saranya , J.Selvakumar, "Implementation of Children Tracking System on Android Mobile Terminals “ , International conference on Communication and Signal Processing, April 3-5, 2013, India

\section{AUTHOR'S BIOGRAPHY}

K.Vidyasagar: Received B. Tech degree in Instrument Technology from Andhra University College of Engineering Visakhapatnam, M.E from P.S.G.Tech Coimbator. He is now a research scholar under the guidance of Dr. A. Bhujangarao, Andhra University. His current research interests include image processing in biomedical instrumentation and related embedded systems.

G.Balaji: Received B.Tech degree in Electronics and communication Engineering from Mother Theresa institute of science and technology. M.Tech from Nova college of Engineering and Technology, jangareddygudem. His current research interest including VLSI and Related Embeded systems.

K. Narendra Reddy: Received B.Tech degree in Electronics and Communication Engineering from sai spurthi Institute of technology, sattupalli . M.Tech from Mother Teresa Institute of Science and Technology, sattupalli. His current research interest in embedded systems. 